\title{
Transplante de células tronco do cordão umbilical: revisão bibliográfica com enfoque do uso no Brasil
}

\author{
Umbilical cord stem cell transplantation: bibliographic review with focus on use in Brazil \\ Transplante de células tronco del cordón umbilical: revisión bibliográfica con enfoque de \\ uso no Brasil
}

Giulia Dalla Bernardina Cardoso ${ }^{1^{*}}$, Altenor Luz Ferreira da Silva ${ }^{2}$, Amanda Samora Gobbi ${ }^{3}$, Bárbara Oliveira Vieira ${ }^{4}$, Gabriel Coelho Soares Moraes ${ }^{5}$, Letícia Lourenço Botelho ${ }^{6}$, Lorena Mattos ${ }^{4}$, Thaís Oliveira Bergamasco ${ }^{7}$, Thales Miranda Sales ${ }^{8}$.

\section{RESUMO}

Objetivo: Abordar a origem das células tronco umbilicais, utilização prática, vantagens, desvantagens e o processo desde o cadastro à captação nos bancos de doação do Brasil. Revisão bibliográfica: A análise se trata do uso terapêutico das células tronco umbilicais com enfoque na realidade brasileira. Por meio dos estudos evidenciou- se que inúmeros são os benefícios, destacando a fácil acessibilidade e a desnecessidade de compatibilidade total entre doador e receptor. Por outro lado, apresentam como desvantagem o uso limitado às pessoas de $50 \mathrm{~kg}$ pela restrição da quantidade de célula captada. No que tange aos bancos de doação, destaca-se a rede pública do Brasil, BrasilCord, a qual é reconhecida pela segurança e eficácia dos transplantes realizados. Considerações finais: Diante do exposto, conclui-se a importância do transplante de células tronco do cordão umbilical, destacando-se sua superioridade quando comparado aos transplantes autólogos convencionais no tratamento de diversas doenças e o protagonismo do Sistema Único de Saúde (SUS) na garantia da realização eficaz da coleta e do processamento das células.

Palavras-chave: Células tronco hematopoiéticas, Cordão umbilical, Bancos de sangue.

\begin{abstract}
Objective: Address the origin of umbilical stem cells, practical use, advantages, disadvantages and the process from registration tofunding in donation banks in Brazil. Bibliographic review: The analysis deals with the therapeutic use of umbilical stem cells with a focuson the Brazilian reality. Through the studies, it was evidenced that there are countless benefits, highlighting the easy accessibility andthe unnecessary total compatibility between donor and recipient. On the other hand, they have the disadvantage of being limited topeople weighing $50 \mathrm{~kg}$ due to the restriction of the amount of captured cell. With regard to donation banks, the public network of Brazil, BrasilCord, stands out, which is recognized for the safety and efficacy of the transplants performed. Final considerations: Given theabove, it is concluded the importance of stem cell transplantation of the umbilical cord, highlighting its superiority when compared toconventional autologous transplants in the treatment of various diseases and the role of the Unified Health System (SUS) inguaranteeing effective collection and processing of cells.
\end{abstract}

Key words: Hematopoietic stem cells, Umbilical cord, Blood banks.

\footnotetext{
1 Universidade Vila Velha (UVV), Vila Velha - ES. *E-mail: giuliadbc@hotmail.com

2 Universidade Politécnica e Artística do Paraguay (UPAP), Ciudad del Este - PY.

${ }^{3}$ Centro Universitário Unifacig (UNIFACIG), Manhuaçu - MG.

${ }^{4}$ Centro Universitário de Caratinga (UNEC), Caratinga - MG.

${ }^{5}$ Universidade Federal de Minas Gerais (UFMG), Belo Horizonte - MG.

${ }^{6}$ Centro Universitário de Valença (UNIFAA), Valença - RJ.

${ }^{7}$ Centro Universitário FAMETRO, Manaus - AM.

8 Universidade Federal de Ouro Preto, Ouro Preto - MG.
} 


\section{RESUMEN}

Objetivo: Abordar el origen de las células madre umbilicales, uso práctico, ventajas, desventajas y el proceso desde el registro hasta la captación de fondos en los bancos de donación en Brasil. Revisión bibliográfica: El análisis aborda el uso terapéutico de las células madre umbilicales con un enfoque en la realidad brasileña. A través de los estudios se evidenció que existen innumerables beneficios, destacando la fácil accesibilidad y la compatibilidad total innecesaria entre donante y receptor. Por otro lado, tienen como desventaja el uso limitado a personas de $50 \mathrm{~kg}$ debido a la restricción de la cantidad de celda capturada. Encuanto a los bancos de donación, se destaca la red pública en Brasil, BrasilCord, que es reconocida por la seguridad y eficacia de los trasplantes realizados. Consideraciones finales: Teniendo encuentalo anterior, se concluye la importância del trasplante de células madre del cordón umbilical, destacando susuperioridad frente a los autotrasplantes convencionales en el tratamiento de diversas enfermedades y el papel del Sistema Único de Salud (SUS) en garantizar una recolección efectiva y procesamiento de células.

Palabras clave: Células madre hematopoyéticas, Cordón umbilical, Bancos de sangre.

\section{INTRODUÇÃO}

As células tronco originam células de todos os tecidos e órgãos do corpo humano, já que apresentam grande capacidade de se diferenciarem em células especializadas e de alta habilidade regenerativa. (PEÇANHA DM, et al, 2017; SANTOS TR, 2021). O uso dessas células é uma prática bastante utilizada no âmbito internacional e pouco conhecida nacionalmente, mas que vem se tornando mais comum com o passar do tempo (AGUIAR JD e ANDRADE SP, 2017).

O uso de células tronco advindas do cordão umbilical revolucionou o tratamento de inúmeras patologias, congênitas ou adquiridas, malignas ou benignas, principalmente as de causa hematológica, como as leucemias (GREER JP, et al, 2014). A capacidade de dar origem a diversos tipos celulares, advém da célula tronco hematopoiética, encontrada no sangue fetal do cordão umbilical, que, por meio da hematopoiese, pode se diferenciar em outras linhagens celulares específicas (HOFFBRAND AV, et al., 2008; GREER JP, et al, 2014).

O cordão umbilical do recém-nascido é uma fonte de dois tipos de células tronco: as hematopoiéticas e as mesenquimais. As células tronco hematopoiéticas são as mesmas encontradas na medula óssea, porém, mais jovens e com a vantagem de não terem sido expostas a vírus, bactérias e ao meio ambiente, o que diminui o risco de complicações e rejeição após o transplante, além de apresentarem uma alta taxa de compatibilidade, tendo a possibilidade de tratamento de inúmeras doenças. Já as células tronco mesenquimais, são encontradas no tecido do cordão umbilical na sua forma mais primitiva (PEÇANHA DM, et al, 2017; SANTOS TR, 2021).

As células hematopoiéticas são retiradas de uma amostra de sangue do próprio cordão umbilical do neonato logo após o nascimento, enquanto as células mesenquimais são removidas de um segmento do cordão umbilical. Após coletadas, as amostras são armazenadas e processadas por um banco de dados em laboratórios especializados para uso posterior (OLIVEIRA FCT e SILVA PDF, 2020).

Para a coleta e armazenamento das células do cordão umbilical, são necessários processos de seleção dos doadores que passam por avaliações para verificação de ausência de doenças transmissíveis e outros dados laboratoriais. Esses processos são necessários para confirmar a segurança e qualidade da doação. Os procedimentos realizados para a coleta são indolores e não expõe a riscos. Após a recolha, o material é enviado para o laboratório de criopreservação, onde irá passar por novos procedimentos para regressão do plasma, e o produto final será realocado para uma bolsa que suporta baixas temperaturas, para que assim seja mantido para sua conservação em um freezer com nitrogênio líquido (OLIVEIRA FCT e SILVA PDF, 2020; AGUIAR JD e ANDRADE SP, 2017; JOMAR RF, 2017).

O transplante de células tronco vai ser classificado de acordo com o doador das células, sendo chamado de alogênico quando as células tronco provêm de outra pessoa, sendo essa parente ou não, e autogênico 
quando as células são colhidas do próprio receptor. Além disso, é dividida em três fases, fase pré-transplante, trans, na qual ocorre a infusão das células tronco, e pós-transplante (FIGUEIREDO A, et al, 2018).

As vantagens do congelamento das células do cordão umbilical são incontáveis, incluindo a substituição de muitos transplantes de medula óssea, que é um procedimento invasivo de extração. Entretanto, apesar dos inúmeros benefícios, existem algumas desvantagens como as limitações por conta do número de células fornecidas pelo cordão umbilical serem insuficientes para reconstruir alguns tecidos em pessoas que pesam mais de 50 quilos, limitando assim, o seu uso (OLIVEIRA FCT e SILVA PDF, 2020).

Diante disso, o presente artigo teve como objetivo realizar uma revisão narrativa da literatura a fim de discutir o funcionamento dos bancos de doação de células tronco do cordão umbilical no Brasil, enfatizando suas vantagens e desvantagens, bem como sua utilização prática.

\section{REVISÃO BIBLIOGRÁFICA}

\section{Células tronco umbilicais}

As células-tronco são células formadas no desenvolvimento embrionário que dão origem a diferentes linhagens celulares. Essa capacidade de proliferação e auto-renovação deve-se ao fato de serem células não especializadas. Podem ser classificadas quanto ao seu potencial de diferenciação em: totipotentes, pluripotentes, multipotentes e unipotentes; e quanto à sua origem em: embrionárias e adultas ou somáticas. Para fazer o uso das células tronco embrionárias é preciso interromper o desenvolvimento embrionário ou a gravidez, já as adultas são de mais fácil acesso, apesar de serem em número reduzido, por serem encontradas vários tecidos e órgãos, como no cordão umbilical e na placenta (OLIVEIRA FCT e SILVA PDF, 2020; ZAKRZEWSKI W, et al., 2019).

As células-tronco adultas, por possuírem uma linhagem de diferenciação predestinada, podendo se diferenciar em qualquer célula do tecido sanguíneo e do sistema imune, é uma das formas mais promissoras de tratamento de muitas doenças hematológicas e imunológicas (JOMAR RF, 2017; OLIVEIRA FCT e SILVA PDF, 2020). A sua obtenção pode ser feita a partir da medula óssea, do cordão umbilical e placentário ou do sangue periférico. Pela dificuldade de serem encontrados doadores compatíveis de medula óssea, além do risco de causar doença do enxerto versus hospedeiro e de transmitir infecções virais, tem sido estimulada a busca de células-tronco no sangue do cordão umbilical e placentário (JOMAR RF, 2017; MENNAN C, et al., 2019; LAROYE C, et al., 2019).

O cordão umbilical é uma estrutura presente nos mamíferos placentários, com aproximadamente 40-60 $\mathrm{cm}$ de comprimento e 1-2 cm de circunferência, que conecta a placenta ao feto fornecendo a nutrição necessária para o desenvolvimento. É composto por uma camada de epitélio que envolve uma veia, duas artérias e o tecido conjuntivo mucóide, denominado geleia de Wharton, sendo que este último compreende a fonte de células tronco no cordão umbilical (DAVIES JE, et al., 2017).

Há, entretanto, uma indefinição científica acerca da delimitação da geleia de Wharton. Nesse sentido, observam-se três distintos entendimentos: um primeiro considerando que a geleia de Wharton compreende todo o tecido, desde as margens externas da túnica média até a superfície interna do epitélio amniótico; um segundo considera apenas a geleia intervascular; e um terceiro exclui o tecido perivascular. Por essa razão, torna-se difícil comparar as características dessas populações de células, bem como as técnicas de isolamento empregadas para coletá-las (DAVIES JE, et al., 2017).

\section{Vantagens e desvantagens do uso das células tronco umbilicais}

O transplante de células tronco obtidas pelo cordão umbilical, tem sido muito utilizado na atualidade devido ao grande sucesso terapêutico, possuindo inúmeros benefícios. Uma das grandes vantagens de se obter células tronco do cordão umbilical é a maior facilidade de encontrar um doador, pois diferente do transplante de medula óssea que necessita de compatibilidade total de Antígeno Leucócitario Humano (HLA), sendo necessário o doador pertencer à mesma família do no transplante de SCUP não se faz necessária compatibilidade total, permitindo que o transplante seja feito mesmo que haja algumas incompatibilidades, 
oferecendo uma logística simples e rápida receptor (RIZK M, et al., 2017; PEÇANHA DM, et al., 2017; PETTERLE RR, et al., 2018).

As células do SCUP possuem alto índice de células tronco hematopoiéticas, que apresentam grande capacidade de regeneração e proliferação, podendo se especializar em qualquer célula do organismo, sendo uma grande vantagem em tratamentos hematológicos e imunológicos, principalmente para pacientes que não encontraram doador compatível na família (GUPTA AO e WAGNER JE, 2020). Além disso, o transplante feito de células do SCUP possui menor incidência de doença do enxerto contra o hospedeiro, que ocorre devido à incompatibilidade do HLA, devido o sangue umbilical possuir baixo número de células T (GUPTA AO e WAGNER JE, 2020; BERGLUND S, et al., 2017).

É necessário frisar a facilidade do transplante autólogo de células obtidas do SCUP, visto que não há necessidade de aguardar um doador compatível ou submeter o doador a um procedimento cirúrgico, já que que as mesmas já estão guardadas no banco de sangue especializado e podendo ser utilizadas de imediato (PETTERLE RR, et. al., 2018).

Inúmeros são os benefícios do transplante de SCUP, entretanto há algumas desvantagens que têm sido notadas e estudadas. A principal delas é que a quantidade de células coletadas do sangue umbilical é pequena, sendo limitada sua aplicação é recomendada apenas para indivíduos com peso de até $50 \mathrm{~kg}$, pois acima desse peso a quantidade de células fornecidas podem ser insuficientes para reconstituição do tecido doente (PEÇANHA DM, et al, 2017).

Outro ponto importante é que está sendo estudado a fim de trazer melhorias ao transplante de SCUP, é a lenta reconstrução do sistema imunológico pós transplante, com maior período de neutropenia, em que torna maior o risco de infecções virais, bacterianas ou fúngicas, sendo as infecções virais, as de maior índice de letalidade (BALLEN K, 2017). Por fim, o alto custo da aquisição dos enxertos de SCUP e dos cuidados hospitalares pós transplante, também é um grande desafio para o sucesso e adesão do transplante de SCUP, podendo chegar a mais de 80.000 dólares (GUPTA AO e WAGNER JE, 2020).

\section{Bancos de doações de células tronco umbilicais}

Em 1988, foi realizado o primeiro transplante bem-sucedido de células tronco obtidas pelo cordão umbilical, sendo comprovado que o sangue de cordão umbilical e placentário (SCUP) é rico em células tronco hematopoiéticas. Após isso, obteve-se a necessidade de criar um banco em que fosse armazenado essas células. Entretanto, apenas em 1993 é que foi inaugurado o primeiro banco de sangue de cordão umbilical e placentário (BSCUP), pelo doutor Pablo Rubinstein, no hemocentro de Nova York, Estados Unidos (PEÇANHA DM, et al, 2017).

Em 1998, a União Europeia criou um banco de pesquisas de células obtidas do sangue de cordão umbilical, chamado Eurocord, em que visava analisar os dados dos transplantes de SCUP realizados na Europa. Dentro do Eurocord, foi criado um grupo chamado Netcord responsável por estabelecer um padrão na coleta, a fim de garantir a qualidade. Após inúmeras pesquisas, em 24 de setembro de 2004, foi criada a primeira rede pública de BSCUP no Brasil, chamada BrasilCord, em que reúne bancos de SCUP públicos de todo Brasil (BALLEN K, 2017).

Os bancos de SCUP são divididos em duas modalidades: pública e privada. Nos bancos públicos, o uso das células é feito por qualquer indivíduo que possua compatibilidade com a mesma e a doação ocorre de forma voluntária, em que uma grávida entra em contato com o banco público e faz a doação. Além disso, todas as despesas do transplante são pagas pelo SUS. Essa modalidade possui uma desvantagem em relação ao setor privado, em que o receptor da doação deverá fazer uso de medicação para evitar que ocorra rejeição do transplante, o que traz despesas e efeitos colaterais da medicação para o mesmo (RODRIGUES RV, 2017; BALLEN K, 2017; PEÇANHA DM, et al, 2017).

Já os bancos privados são destinados ao uso pessoal, em que as células serão armazenadas para uso no futuro, se houver necessidade e todas as despesas da coleta, armazenamento e transplante serão de responsabilidade pessoal. Entretanto, se o responsável pelo material autorizar, o transplante também pode 
ser feito para outro indivíduo, desde que seja compatível. A vantagem do transplante no setor privado é que não necessita fazer o uso da medicação antirrejeição, pois não há rejeição do sistema imune (RODRIGUES RV, 2017; BALLEN K, 2017). Os transplantes feitos no setor público são os que estão em maior número, pois os custos do setor privado são altos e poucas pessoas podem arcá-los (PEÇANHA DM, et al, 2017).

\section{Uso das células tronco umbilicais no brasil}

Para a doação das células tronco na rede pública do Brasil, é necessário que a gestante tenha o parto em uma das maternidades com credenciamento na rede BrasilCord. Esse credenciamento assegura que 0 material seja coletado e armazenado da maneira adequada, pois somente os profissionais da rede possuem o treinamento técnico necessário. Atualmente 15 bancos públicos são distribuídos pelas regiões do país, no entanto, a coleta pode ser realizada em todas as maternidades credenciadas (GONÇALVES AJG, 2019).

Em suma, o sangue retirado do cordão umbilical é devidamente controlado, sendo primeiramente quantificado o número de células e após a comprovação do número necessário, os testes da HLA e de doenças infectocontagiosas são realizados. Em conseguinte o material é criopreservado, e no que tange a disponibilidade para a doação, só será possível após passar por todos os critérios de elegibilidade (REGISTRO NACIONAL DE DOADORES DE MEDULA ÓSSEA (REDOME), 2021; SHEARER WT, et al, 2017).

Pelo SUS, rede BrasilCord a doação é realizada gratuitamente, podendo ser transplantado em qualquer paciente necessitado. Quando os pais fazem a doação (heterólogo) ao banco público, a coleta fica armazenada. O valor do armazenamento gira em torno de $\mathrm{R} \$ 3$ mil para o SUS e a importação internacional de unidades de sangue de cordão umbilical, possui um gasto em torno de $R \$ 80$ mil. Outra modalidade existente é a de doação familiar direcionada, quando é utilizado para o benefício de um irmão necessitado a receber a doação (PIRES AN, et al, 2015; REDOME, 2021).

No banco de sangue privado, são variáveis as regulamentações, tendo o propósito de cunho comercial. Nesse ínterim, os transplantes são autólogos, logo, o sangue é utilizado para o próprio doador ou pode ser destinado para o tratamento de parentes em casos de compatibilidade genética com a devida autorização dos pais. Uma taxa única é cobrada para cobrir os gastos procedimentais e registro, além disso, são cobradas taxas periódicas para o armazenamento do sangue (PIRES AN, et al, 2015).

O Ministério da Saúde preconiza que o transplante de sangue de cordão na rede pública é sem dúvida mais seguro que em bancos privados. Haja vista, que não existem publicações extensas corroborando bons resultados obtidos através do uso de cordões armazenados em bancos privados. O contrário do que acontece com os incontáveis estudos comprovando a eficácia dos transplantes realizados nos bancos da rede pública (GONÇALVES AJG, 2019; INSTITUTO NACIONAL DO CÂNCER (INCA), 2021; REDOME, 2021). Portanto, os Órgãos Internacionais não investem em bancos privados, já a rede pública é reconhecida pelos melhores procedimentos para a coleta, armazenamento e doação do sangue, tendo apoio mantenedor governamental e internacional (INCA, 2021; REDOME, 2021).

Decerto, todo o procedimento de regulamentação dos Bancos de SCUP no Brasil é realizado pela Agência Nacional de Vigilância Sanitária pela resolução - RDC/ANVISA 153 de 14 de junho de 2004 juntamente da RDC 56/2010, onde as exigências de qualidade e segurança são seguidas durante a rotina que incluem os testes sorológicos de alta sensibilidade para detecção de infecções transmissíveis pelo sangue; testes microbiológicos; contagem do número de células nucleadas e eritroblastos quando necessário; testes de viabilidades e fenotipagem celular quantificando as células com o marcador CD34+; testes funcionais quando preciso e caracterização molecular (CRUZ LE, et al., 2009).

A técnica do transplante ocorre similarmente à realizada na doação de medula. Após o paciente passar pelo processo de preparo da quimioterapia ou radioterapia, ele recebe as células-tronco, sendo transfundido semelhantemente ao modo da transfusão sanguínea. Pacientes com indicação para transplante que não possui um grau de parentesco com o doador necessitam de cadastrar no Registro Nacional de Receptores de Medula Óssea (REREME), assim, o médico registra no sistema as os dados cadastrais do paciente, as características da doença e o resultado do teste de HLA. O próximo passo será identificar um doador ou uma 
unidade de cordão compatível, que ocorre através do cruzamento de dados entre o REREME, o REDOME, os dados das unidades armazenadas em bancos da Rede BrasilCord e dos doadores voluntários (INCA, 2021; REDOME, 2021).

Atualmente, existem cerca de 5 milhões de unidades de SCUP em todo o mundo, sendo que 800 mil estão em bancos públicos e mais de 4 milhões estão em bancos privados (GUPTA AO e WAGNER JE, 2020). Conforme demonstram os dados do REDOME, os bancos públicos de sangue de cordão têm aumentado progressivamente, proporcionalmente o mesmo ocorre com os registros de doadores voluntários. No que tange à compatibilidade, cerca de $80 \%$ dos pacientes que precisam do transplante não aparentado conseguem doadores (REDOME, 2021). Segundo dados colhidos no Instituto Nacional do Câncer (INCA), das 23.923 mil bolsas armazenadas nas unidades em funcionamento, 187 já foram utilizadas para transplantes e desse total de transplantados, $70 \%$ da fonte de células são do Brasil e os outros 30\% são do exterior (INCA, 2021).

\section{CONSIDERAÇÕES FINAIS}

Considerando os dados expostos acima, pode-se afirmar que o uso de células tronco do SCUP tem se mostrado benéfico em diversos âmbitos do tratamento de doenças hematológicas em comparação ao transplante autólogo de medula convencional, apesar de ainda possuir algumas desvantagens como a restrição de peso e uma possível reconstrução imunológica mais vagarosa. Nesse contexto, os bancos de SCUP de governança pública assumem o protagonismo na coleta, processamento e armazenamento, além de apresentarem bons resultados de maneira consistente nos últimos anos. No Brasil tal prática é contemplada pelo SUS, que possui 15 bancos públicos distribuídos pelo território nacional, trazendo inúmeros benefícios, dentre eles financeiro, para a manutenção da prática no país. Pode-se concluir que o transplante de SCUP é uma prática bem consolidada internacionalmente, entretanto novos estudos são necessários para aprimorar e suprir as atuais insuficiências presentes, como a inviabilidade do procedimento em pessoas com mais de $50 \mathrm{~kg}$.

\section{REFERÊNCIAS}

1. AGUIAR JD, ANDRADE SP. Uso de Células-Tronco fetais no tratamento da leucemia. Anais da 20 Jornada Científica da Biologia e do $1^{\circ}$ Encontro Técnico-Científico da Faculdade Guaraí (IESC), 2017; 7(2): 74-82.

2. BALLEN K. Transplante de sangue do cordão umbilical: desafios e direções futuras. Células-tronco TransIMed., 2017; 6(5): 1312-1315.

3. BERGLUND S, et al. Avanços na terapia com células do sangue do cordão umbilical: o presente e o futuro. Expert OpinBiolTher, 2017; 17(6): 691-699.

4. CRUZ LE, et al. Sangue de cordão umbilical para uso autólogo ou grupo de pacientes especiais. Revista brasileira de hematologia e hemoterapia, 2009; 31: 36-44.

5. DAVIES JE, et al. Concise Review: Wharton's Jelly: The Rich, but Enigmatic, Source of Mesenchymal Stromal Cells. Translational Medicine, 2017; 6: 1620-1630.

6. FIGUEIREDO A, et al. Reações adversas no dia zero do transplante de células-tronco hematopoéticas: revisão integrativa. Revista Gaúcha de Enfermagem, 2018.

7. GONÇALVES AJG. Avaliação do grau de conhecimento das gestantes da Grande Florianópolis sobre sangue de cordão umbilical, seu uso e armazenamento. Dissertação (graduação em medicina). Universidade Federal de Santa Catarina, Florianópolis, 2019; 43 p.

8. GUPTA AO, WAGNER JE. Umbilical Cord Blood Transplants: Current Status and Evolving Therapies. Frontiers in Pediatrcs, 2020; 8: 570282.

9. GREER JP, et al. Wintrobe's Clinical Hematology. 13 Williams \& Wilkins Health, 2014.

10. HOFFBRAND AV, et al. Fundamentos em hematologia. $5^{\underline{a}}$ ed. Porto Alegre: Artmed, 2008.

11. INSTITUTO NACIONAL DO CÂNCER (INCA). Perguntas frequentes: Sangue de cordão umbilical. 2021. Disponível em: https://www.inca.gov.br/perguntas-frequentes/sangue-de-cordao-umbilical?page=1. Acessado em: 3 de maio de 2021.

12. JOMAR RF. Obtenção de células-tronco hematopoiéticas do sangue de cordão umbilical e placentário: papel do enfermeiro. Enfermagem Brasil, 2017; 16 (2): 123- 128.

13. LAROYE C, et al. Bone marrow vs Wharton's jelly mesenchymal stem cells in experimental sepsis: a comparative study. Stem Cell Res Ther, 2019; 10: 192. 
14. MENNAN C, et al. A comprehensive characterisation of large-scale expanded human bone marrow and umbilical cord mesenchymal stem cells. Stem Cell Res Ther, 2019; 10: 99.

15. OLIVEIRA FCT, SILVA PDF. Células-tronco Hematopoiéticas e seu Armazenamento em Bancos de Sangue de Cordão Umbilical e Placentário. ACET científica, 2020.

16. PEÇANHA DM, et al. Importância do conhecimento sobre células tronco de cordão umbilical para a saúde. Revista EletronicaMultivix, 2017.

17. PETTERLE RR, et al. Fatores associados ao tempo de sobrevida de crianças e adolescentes pos transplante de sangue de cordão umbilical. Revista Brasil Biomedicina, 2018; 36(1): 20-25.

18. PIRES AN, et al. A importância do sangue do cordão umbilical e placentário (SCUP) e dos bancos de sangue do cordão umbilical e placentário (BSCUP). Revista Eletrônica de Farmácia, 2015; 13(1.1): 94-95.

19. REGISTRO NACIONAL DE DOADORES DE MEDULA ÓSSEA (REDOME). Perguntas e Respostas Cordão Umbilical. 2021. Disponível em: http://redome.inca.gov.br/cordao-umbilical/perguntas-e-respostas-cordao-umbilical/. Acessado em: 4 de abril de 2021.

20. RIZK M, et al. Cell-Based Therapy Using Umbilical Cord Blood for Novel. Indications in Regenerative Therapy and Immune Modulation: An Updated Systematic Scoping Review of the Literature. BiolBloodMarrowTransplant, 2017; 23(10):1607-1613.

21. RODRIGUES RV. Capitalização da vida nos bancos de células-tronco umbilicais: interrogantes à Psicologia na produção subjetiva. Estud. pesqui. psicol., 2017; 17(3): 1005-1021.

22. SANTOS TR. Impacto do armazenamento prolongado de amostras fixadas de sangue de cordão umbilical na quantificação de células-tronco hematopoiéticas por Citometria de Fluxo. ACET científica; 2021.

23. SHEARER WT, et al. Cord Blood Banking for Potential Future Transplantation. Pediatrics, 2017; 140(5): 1-15.

24. ZAKRZEWSKI W, et al. Stem cells: past, present, and future. Stem Cell Res Ther, 2019; 10: 68. 